in vivo $35: 31-39(2021)$

doi:10.21873/invivo.12229

Review

\title{
Circulating Tumor Cells, Circulating Tumor DNA and Other Blood-based Prognostic Scores in Pancreatic Ductal Adenocarcinoma - Mini-Review
}

\author{
MARIAN LIBERKO ${ }^{1,2}$, KATARINA KOLOSTOVA $^{3}$, ARPAD SZABO ${ }^{4}$, ROBERT GURLICH $^{5}$, \\ MARTIN OLIVERIUS ${ }^{5}$ and RENATA SOUMAROVA ${ }^{1,2}$ \\ ${ }^{1}$ Department of Radiotherapy and Oncology, University Hospital Kralovske Vinohorady, Prague, Czech Republic; \\ ${ }^{2}$ Third Faculty of Medicine, Charles University in Prague, Prague, Czech Republic; \\ ${ }^{3}$ Department of Laboratory Genetics, Laboratory Diagnostics, \\ University Hospital Kralovske Vinohrady, Prague, Czech Republic; \\ ${ }^{4}$ Department of Pathology, Third Faculty of Medicine, \\ Charles University in Prague and University Hospital Kralovske Vinohrady, Prague, Czech Republic; \\ ${ }^{5}$ Department of General Surgery, University Hospital Kralovske Vinohrady, Prague, Czech Republic
}

\begin{abstract}
Pancreatic ductal adenocarcinoma represents a disease with increasing incidence. Its prognosis is the worst among all malignancies despite the aggressive combined multimodal treatment across all stages. In metastatic disease, median survival is approximatelly one year. The mainstay of treatment is chemotherapy (neo/adjuvant, palliative) and in selected subgroups of patients even radiotherapy. Nevertheless, nowadays there are very few prognostic and/or predictive biomarkers available that can be used to identify and better stratify patients based on risk to tailored treatment. Potentially, promising areas of research are circulating tumor cells and circulating tumor DNA, which can be easily obtained from peripheral blood - so called liquid biopsy. They may serve as a tool to assess response to applied treatment, and to detect the emergence of treatmentresistant clones or early disease relapse. Moreover, their study may allow identification of potentially tumor-specific alterations, which may serve as target structures for targeted (tailored) therapy. Alternatively, different prognostic
\end{abstract}

This article is freely accessible online.

Correspondence to: Marian Liberko, Third Faculty of Medicine, Charles University in Prague, Prague, Czech Republic. E-mail: marian.liberko@fnkv.cz

Key Words: Pancreatic carcinoma, circulating tumor cells (CTC), circulating tumor DNA (ctDNA), prognostic index/score, liquid biopsy, biomarkers, review. indexes/scores calculated by analysis of selected parameters of blood and/or biochemistry can be used to better stratify patients based on risk and better predict prognosis. The aim of this mini-review is to provide a basic overview of the current state of the art in this area and its potential significance for clinical practice.

Pancreatic ductal adenocarcinoma represents a disease with dismal prognosis across all its stages. Its incidence and mortality is rising and it is expexted that within the next decade (in year 2030) it will become the second most common cause of death among malignancies $(1,2)$. Pancreatic ductal adenocarcinoma may be diagnosed in 4 different stages: resectable, borderline resectable, locally advanced and metastatic disease (3). Surgery represents the only potentially currative approach for resectable pancreatic ductal adenocarcinoma. In other clinical stages surgery is/may be considered as a potentially currative treatment (patients with borderline resectable pancreatic cancer who responded well to neoadjuvant treatment), or as a palliative method (by-pass surgery, e.g. gastroenteroanastomosis) in patients with locally advanced or metastatic disease.

Due to asymptomatic or non-specific symptoms in early stages, most patients are diagnosed in advanced stages (borderline resectable, locally advanced or metastatic carcinoma). In advanced stages, oncological treatment (chemotherapy, radiotherapy, chemoradiotherapy) is preffered over surgery. Current standard of treatment for inoperable patients is chemotherapy and in selected subgroups of patients even radiotherapy. Radioterapy can be used 
sequentially for patients without early progression after 3-6 months of so called "induction" chemotherapy, specifically in subgroup of patients with rather indolent disease with predominance to local or locoregional progression. In that case, the aim of radiotherapy is to increase local control rate and to allow a "chemotherapy-free period" of treatment.

Chemotherapy is nowadays still the leading modality of oncological treatment for patients across all stages of disease. In the last few years, there is a lot of improvement/research in this area, which resulted in improved survival rates. Besides standard adjuvant chemotherapy (gemcitabine), combination regimens are available, which result in increase in the response rate, prolongation of progression-free survival (PFS) and overall survival (OS). In the adjuvant setting, the new options are the combination of gemcitabine + capecitabine (4) and mFOLFIRINOX (5). For the treatment of metastatic pancreatic ductal adenocarcinoma there is, besides gemcitabine monotherapy, the option of the combination such as gemcitabine + nab-paclitaxel (6), and for patients in very good clinical condition, without limiting comorbidities, the mFOLFIRINOX regimen (7). The new regimen for second line treatment, after progression to gemcibine-based regimen, is the nanoliposomal formulation of irinotecan in combination with 5-fluorouracil (8). Pancreatic carcinoma, in contrast to other malignancies, was not considered for treatment with targeted agents until recently. The results of a study of patients with $B R C A 1 / 2$ mutations who were treated with the targeted agent olaparib was recently published (9).

Furthermore, despite the current progress in systemic treatment of pancreatic carcinoma, there are very few prognostic and predictive biomarkers available for routine clinical use to tailor treatment with the aim to improve survival of these patients.

In this mini-review, we present the results of studies evaluating the benefits of new biomarkers [circulating tumor cells (CTC), circulating tumor DNA (ctDNA)] and prognostic scores (prognostic score/index), which may allow better stratification and individualized treatment for these patients.

\section{Search Strategy and Selection Criteria}

Our research strategy was aimed at evaluating studies on the role of circulating biomarkers in patients with pancreatic carcinoma. Scientific articles from year 2000 to 2020 were searched using the PubMed and Web of Science databases. All searches were up to April 2020. The search terms used included "circulating tumor cells", "circulating tumor DNA", "prognostic markers in pancreatic carcinoma", "systemic inflammatory response in pancreatic carcinoma", and "NLR, PLR and prognosis in pancreatic carcinoma". Only English language papers were reviewed.

\section{Circulating Tumor Cells in Pancreatic Ductal Adenocarcinoma}

CTCs are cells shed to the blood stream either from a primary tumor or its metastases. Their isolation and subsequent quantitave and qualitative analysis across different stages of disease have proved their prognostic and predictive significance in different malignancies (10). CTCs may serve as a liquid biopsy, and provide data regarding the presence of minimal residual disease after surgery or after completion of adjuvant treatment and therefore, identify patients with high risk of relapse. Moreover, they may be used to monitor the effect of ongoing treatment, to reveal resistance to treatment, or even to detect relapse early. Their further molecular characterisation allows the study their specific molecular alterations, and subsequently it can lead to the preparation of targeted therapy, targeting alterations in these cells, which are considered to be precursors of metastatic foci. Finally, their study may result in individualised treatment, thus, leading to improvement in survival in patients with this malignancy.

There are a lot of methods to isolate and detect CTC from peripheral blood of patients with cancer. The most common methods are based on immunomagnetic separation of cells, whereas another technique relies on cell size-based filtration. Advantages and disadvantages of these methods have been reviewed elsewhere (10).

There are a lot of studies evaluating the impact of CTC presence in the peripheral blood of patients with pancreatic cancer on PFS and OS. They have proven that CTCs are independent predictors of prognosis and may allow better stratification of patients than classical parameters (TNM classification, imaging methods, Ca19-9 levels).

Effenberger et al. evaluated 69 patients with pancreatic carcinoma. The presence of CTCs was confirmed in 23 out of 69 patients $(33.3 \%)$. CTC-positive patients had significantly shorter PFS and OS in univariate analysis ( $p=0.009$ for PFS, $p=0.030$ for OS) and in multivariate analysis $(\mathrm{HR}=4,543, p=0.006$ for $\mathrm{PFS}$ and $\mathrm{HR}=2,093$, $p=0.028$ for OS). The prognostic significance of CTCs in this study was confirmed even in patients treated with chemotherapy. PFS was significantly shorter in CTC-positive patients in univariate $(p=0.013)$ and in multivariate analysis $(\mathrm{HR}=4,203, p=0.010)$. Moreover, four patients without CTCs were alive after 36 months (11).

Besides identification of patients with worse prognosis, there are also studies showing that the presence of CTCs in the peripheral blood of patients may predict occult metastatic spread better, or even earlier than classic imaging methods (12). Court et al. have evaluated 126 patients (100 with pancreatic cancer and 26 with benign lesions) and assessed the association of CTC presence and occult metastatic spread and prognosis. CTCs were detected in $78 \%$ of patients and 
the number of CTCs correlated with stage of disease $(p<0.001)$. Out of 53 patients, who were (based on regular imaging methods) indicated for potentially currative surgery, $13(24.5 \%)$ were confirmed with metastatic disease during surgery. Patients with occult metastatic disease had significantly more CTCs than patients with locally advanced disease (median 7 vs. 1 CTC, $p<0.0001$ ). The presence of CTC allowed the identification of patients with occult metastatic disease preoperatively $(p<0.0001)$. Moreover, CTCs were independent predictor of DFS in univariate analysis $(\mathrm{HR}=2.36, p=0.017)$ and also independent predictor of OS in multivariate analysis $(\mathrm{HR}=1.38, p=0.040)(12)$.

Similar results indicating the prognostic significance of CTCs in patients with pancreatic carcinoma had already been published in 2 large metaanalyses, comprising more than 600 patients each. They proved the association of CTC positivity and worse survival. The first of them proved clearly worse OS $(\mathrm{HR}=1.64, p<0.00001)$ and PFS $(\mathrm{HR}=2.36, p<0.00001)$ in CTC-positive patients. CTCs were also associated with worse prognosis across all analyzed subgroups (before, during and after treatment) and post-treatment CTCs were the most significant predictor of a poor PFS $(\mathrm{HR}=8.36$, $p<0.0001)(13)$. The second metaanalysis that comprised 623 patients showed that CTC-positive patients had worse PFS $(\mathrm{HR}=1.89, p<0.001)$ and $\mathrm{OS}(\mathrm{HR}=1.23, p<0.001)(14)$.

CTCs are a heterogenous population with a different potential to generate metastatic lesions. Some CTCs present signs/markers of so called tumor initiating cells, which are probably responsible for distant dissemination.

Amantini et al. have evaluated CTCs in the blood of 20 patients with pancreatic carcinoma during treatment. They found, that patients with a high number of CTCs (above 10 CTCs/ml) before initiation of chemotherapy had shorter OS than patients with a lower number of CTCs (below 10 $\mathrm{CTC} / \mathrm{ml}),(p<0.0006)$ and showed a trend for shorter PFS $(p<0.067)$. They also evaluated the gene expression profile of CTCs in patients before and after chemotherapy. They found, that during chemotherapy there were changes in the expression of 19 genes. Among them, were genes related to stemness, aggressiveness, ability to invasion and epithelialto-mesenchymal transition (EMT) - markers of bad prognosis. Results showed, that by applying chemotherapy, mesenchymal-like CTCs were found in the peripheral blood of patients, and that they signal increased aggressiveness of disease and resistance to applied treatment. Specifically, there was an increase in the rate of patients with mesenchymal-like CTCs, from 5\% before chemotherapy to $16 \%$ after chemotherapy. Their phenotype was described as having high levels of CD44 and ALCAM, markers of cancer stemm cells or tumor initiating cells (15).

Similarly, Zhao et al. have evaluated the presence of phenotypically different CTCs in the peripheral blood of 107 patients with pancretic carcinoma. They identified 3 groups of CTCs. Epithelial CTCs (E-CTC), epithelial-mesenchymal, or hybrid CTCs (E/M-CTC, H-CTC) and mesenchymal CTCs (M-CTC). E-CTC were present in 65 (60.7\%), E/M CTC in $39(36.4 \%)$ and M-CTC in $49(45.8 \%)$ patients. The presence of M-CTC correlated positively with TNM stage $(p<0.01)$ and distant metastases $(p<0.01)(16)$.

Similar results indicating that CTCs with markers of tumor initiating cells or cancer stemm cells are responsible for bad prognosis of patients were also obtained in another study. Porouk et al. examined the peripheral blood of 60 patients with pancreatic carcinoma for the presence of tumor initiating cells. These cells were identified by means of immunofluorescence positivity for CD133, CD44 and ALDH. Forty-seven of patients (78\%) were positive for at least one marker of tumor initiating cells. ALDH-positive and triplepositive CTCs were independent predictors of relapse and were associated with shorter survival without progression. ALDH-positive CTCs were associated with higher risk of recurrence/relapse $(\mathrm{HR}=3.37, p=0.03)$ and median DFS was 9.7 months in patients with ALDH-positive CTCs, meanwhile in patients without ALDH-negative CTC median was not reached $(p=0.03)$. Moreover, patients with triple-positive CTCs had a higher risk of recurrence/relapse than patients without these CTCs $(\mathrm{HR}=6.4, p<0.01)$. Median DFS in the triple-positive CTC group was 9.3 months compared to 19.8 months in the group without these CTCs $(p=0.001)$. In this study, ALDH-positive and triple-positive CTCs were found to have prognostic significance for OS $(p<0.01)(17)$.

Finally, Bobek et al. examined the blood of 24 patients with pancreatic cancer who were potential candidates for surgery. They identified CTCs in 16 out of 24 patients (66.7\%). CTC positivity did not reflect disease stage, tumor size or lymph node involvement. By using the size-based filtration method they were able to cultivate CTCs for further downstream analysis. They also found, that some of the CTCs displayed plasticity which enabled some cells to invade separating membrane, representing thus a more invasive fraction of CTCs (18). The main results of studies on CTCc in pancreatic ductal adenocarcinoma are summarized in Table I.

\section{Circulating Tumor DNA (ctDNA) in Pancreatic Ductal Adenocarcinoma}

With the improvenent in molecular-genetic methods circtulating tumor DNA (ctDNA) can be detected and isolated for further analysis. There is a growing body of evidence, that specific genetic and epigenetic alterations in ctDNA may be markers of early detection of malignancy and assessment of treatment response in real-time, and a tool to better stratify patients. Furthermore, the identification of specific mutations in the ctDNA may also allow evaluation of the efficacy of new personalized targeted agents. 
in vivo $35: 31-39(2021)$

Table I. Studies evaluating the impact of CTC on outcome of pancreatic carcinoma patients.

\begin{tabular}{|c|c|c|c|}
\hline Author & $\begin{array}{l}\text { Number of } \\
\text { patients }\end{array}$ & $\begin{array}{c}\text { CTC } \\
\text { positivity }\end{array}$ & Main findings \\
\hline Effenberger (11) & 69 & $23 / 69(33.3 \%)$ & $\begin{array}{l}\text { Median OS } 8 \text { months in CTC }+v s . \text { median OS } 12 \text { months in CTC-; } p=0.030 \\
\text { HR=2.093 for OS in multivariate analysis; } p=0.028 \\
\text { Median PFS NR in CTC }+v s . \text { median PFS NR in CTC-; } p=0.009 \\
\text { HR } 4.53 \text { for PFS in multivariate analysis; } p=0.006\end{array}$ \\
\hline Court (12) & 126 & $78 / 100(78 \%)$ & $\begin{array}{l}\mathrm{HR}=1.69 \text { for } \mathrm{OS} \text { in univariate analysis; } p<0.001 \\
\mathrm{HR}=2.36 \text { for PFS in univariate analysis; } p=0.017 \\
\mathrm{HR}=1.38 \text { for OS in multivariate analysis; } p=0.040 \\
\text { in } 13 / 53(24,5 \%) \text { patients, CTC }+ \text { predicted occult metastatic spread at surgery; } p<0.0001\end{array}$ \\
\hline Ma (13) & 603 & NR & $\begin{array}{l}\mathrm{HR}=1.64 \text { for } \mathrm{OS} ; p<0.00001 \text { (whole cohort) } \\
\mathrm{HR}=2.36 \text { for } \mathrm{PFS} ; p<0.00001 \text { (whole cohort) } \\
\mathrm{HR}=2.20 \text { for } \mathrm{OS} ; p=0.13 \text { (post treatment) } \\
\mathrm{HR}=8.36 \text { for PFS; } p<0.0001 \text { (post treatment) }\end{array}$ \\
\hline Han (14) & 623 & $268 / 623(43 \%)$ & $\begin{array}{l}\mathrm{HR}=1.23 \text { for } \mathrm{OS} ; p<0.001 \\
\mathrm{HR}=1.89 \text { for } \mathrm{PFS} ; p<0.001\end{array}$ \\
\hline Amantini (15) & 20 & $20 / 20(100 \%)$ & $\begin{array}{l}\text { Shorter OS in patients with over } 10 \mathrm{CTC} / \mathrm{ml} v s \text {. below } 10 \mathrm{CTC} / \mathrm{ml} ; p<0.0006 \\
\text { Shorter PFS in patients with over } 10 \mathrm{CTC} / \mathrm{ml} v s . \text { below } 10 \mathrm{CTC} / \mathrm{ml} ; p<0.067 \\
\text { Increase in CTC with aggressive phenotype (CD } 44+\text {, ALCAM+) } \\
\text { during treatment } 5 \% \rightarrow 16 \%\end{array}$ \\
\hline Zhao (16) & 107 & $84 / 107(78.5 \%)$ & $\begin{array}{l}\text { Shorter OS in patients with over } 6 \mathrm{CTC} / \mathrm{ml} v s \text {. below } 6 \mathrm{CTC} / \mathrm{ml} \\
(11 \text { vs. } 18 \text { months), } \mathrm{HR}=0.54 ; p<0.001 \\
\text { Shorter PFS in patients with over } 6 \mathrm{CTC} / \mathrm{ml} \text { vs. below } 6 \mathrm{CTC} / \mathrm{ml} \\
(8 \text { s. } 13 \text { months), } \mathrm{HR}=0.52 ; \mathrm{p} \text {-value NR } \\
\text { Epithelial CTC } 65 / 107(60.7 \%) \\
\text { Epithelial/mesenchymal CTC } 39 / 107(36.4 \%) \\
\text { Mesenchymal CTC } 49 / 107(45.8 \%) \text { - significant correlation with TNM }(p<0.01), \mathrm{M} 1 \quad(p<0.01)\end{array}$ \\
\hline Poruk (17) & 60 & $47 / 60(78 \%)$ & $\begin{array}{l}\text { ALDH+, or tripple+ CTC show significant correlation with OS; } p<0.01 \\
\text { Median PFS } 9.7 \text { months in ALDH+ CTC } v s . \text { not reached in ALDH- CTC, HR=3.37; } p=0.03 \\
\text { Median PFS } 9.3 \text { months in tripple+ CTC } v s .19 .8 \text { months in tripple- CTC, HR=6.4; } p=0.001\end{array}$ \\
\hline Bobek (18) & 2 & $16 / 24(66.7 \%)$ & $\begin{array}{l}\text { Some of CTC were able to invade separating membrane, representing thus } \\
\text { more invasive fraction of CTC }\end{array}$ \\
\hline
\end{tabular}

CTC: Circulating tumor cells; OS: overall survival; PFS: progression-free survival; HR: hazard ratio; NR: not reported.

ctDNA is usually double-stranded, consists of small fragments (70-200 base pair) and larger fragments with a molecular weight of about $211 \mathrm{~kb}$, and is present in both the plasma and the serum.It has been suggested that ctDNA originates from cells undergoing apoptosis, necrosis or proliferation, and also from the lysis of CTCs. In many malignancies, there is an increase in cell turnover and apoptosis, leading to significantly higher levels of ctDNA in this group of patients compared to those in the healthy population (19).

In pancreatic cancer, 4 genes are most commonly mutated: $K R A S, C D K N 2 A, S M A D 4$ and TP53. Most studies that evaluated the impact of ctDNA on the prognosis of patients with pancreatic carcinoma were based on the detection of KRAS mutations, which occurred in about $90-95 \%$ of cases.

Kruger et al. have examined the presence of mtKRAS ctDNA in the blood of patients with pancreatic carcinoma treated with chemotherapy (gemcitabine). In their study, comprising 54 patients, ctDNA was detected in $36(67 \%)$ of them. The presence of ctDNA significantly correlated with shorter PFS and OS in patients treated with gemcitabine. A change in the concentration (kinetics) of ctDNA during treatment was able to predict response earlier than the markers CEA and Ca19-9. A decrease in ctDNA concentration during the first month of treatment was an indicator of early response to treatment, meanwhile the correlation between the kinetics of CEA, Ca19-9, CYFRA 21-1 and response was not observed (20).

A similar study evaluating the potential of ctDNA was performed in patients with resected pancreatic carcinoma, who were about to start adjuvant treatment. ctDNA was detected in 23 of $37(62 \%)$ patients preoperatively, and in 13 out of $35(37 \%)$ patients postoperatively. Preoperatively, the presence of ctDNA $v s$. no ctDNA was associated with a higher risk of recurrence, median PFS of 10.3 months $v s$. not reached $(\mathrm{HR}=4.1, p=0.003)$, and also with worse OS, 13.6 months vs. not reached $(\mathrm{HR}=4.1, p=0.015)$. By univariate and multivariate analysis, only the presence of ctDNA 
showed statistically significant relation to recurrence, relapse and OS. Similarly, postoperatively, the presence of ctDNA $v s$. no ctDNA after resection was associated with shorter time to reccurence $5.4 v s .17 .1$ months $(\mathrm{HR}=5.4, p<0.001)$ and shorter OS, 10.6 months $v s$. not reached $(\mathrm{HR}=4.0$, $p=0.003$ ). During a median follow-up of 38.4 months, 10 out of 22 patients with negative ctDNA after resection recurred, meanwhile in the group of ctDNA-positive patients, 13 out of $13(100 \%)$ recurred. Moreover, this prognostically unfavourable subgroup using doublet chemotherapy in the adjuvant setting, showed a trend towards prolongation of PFS to 10.1 months $v s$. 5.1 months with gemcitabine monotherapy $(p=0.15)(21)$.

A recently published study evaluated the importance of ctDNA in 104 patients with metastatic pancreatic carcinoma. This study also confirmed the prognostic significance of ctDNA. Detectable ctDNA was associated with significantly shorter PFS $(\mathrm{HR}=1.93, p=0.012)$ and $\mathrm{OS}(\mathrm{HR}=2.36$, $p=0.018)(22)$.

The presence of ctDNA (and mainly changes in concentration of ctDNA during treatment) and its role in the prediction of prognosis and response to treatment was evaluated in the study of Watanabe et al. They longitudinally evaluated ctDNA and Ca19-9 in a group of 39 patients, who underwent surgery. Twenty-two of the patients recurred and Fisher exact test indicated that the increase in Ca19-9 levels was significantly associated with recurrence or relapse $(p<0.0001)$. Nevertheless, the increased levels of Ca19-9 were not associated with the prognosis of these patients $(p=1.0)$. However, the appearance of ctDNA during the longitudinal follow-up was associated with prognosis $(p<0.001)$ regardless of recurrence/relapse. In a subgroup of 39 patients, who did not undergo surgery, Fisher exact test indicated that detection of ctDNA during the longitudinal follow-up was associated with prognosis $(p=0.005)$, meanwhile Ca19-9 levels were not $(p=0.692)$. Moreover, changes in the concentration of ctDNA during the first 6 months of chemotherapy were able to predict response to treatment, while changes in Ca19-9 levels were not (23). The inverse correlation between the concentration of ctDNA and the survival of patients was also confirmed in other studies $(24,25)$.

Recently, the interesting study of Patel et al. was published. They evaluated the presence of ctDNA and its correlation with prognosis. Moreover, they also evaluated the possibility of treatment based on alterations detected in ctDNA. The presence of ctDNA was again found to be a negative prognostic factor. They showed that the most common mutations detected in the ctDNA were in TP53 and $K R A S$ genes and that patients with advanced pancreatic carcinoma had significantly more alterations present in the ctDNA than patients with resectable stages of disease (median 2 vs. 0,5, $p=0.04$ ). Moreover, in this study, treatment based on the analysis of mutations present in the ctDNA was applied. In a patient with alterations in 3 genes affecting the MEK pathway (GNAS, KRAS and NF1), 6 months of response to trametinib was achieved (26). The main results of studies on ctDNA in pancreatic ductal adenocarcinoma are summarized in Table II.

\section{Other Prognostic and Predictive Markers in Pancreatic Ductal Adenocarcinoma}

Besides the role of CTCs and ctDNA as predictive and prognostic markers, there are also other, generally cheap and easy to measure parameters to obtain prognostic scores, indexes and nomograms, which can be used to better stratify patients and identify those with a good or bad prognosis. Most of these prognostic scores evaluate different values of common laboratory parameters, for example blood count and/or specific biochemical parameters. Most of them are assessing/evaluating the influence of systemic inflammatory response, which is common in cancer, in regard to different parameters of treatment, PFS and OS.

\section{Systemic Inflammatory Response Index (SIRI)}

SIRI was initially evaluated in patients with hepatocellular carcinoma following tumor resection (27). Other separate indexes, such as neutrophil-to-lymphocyte ratio (NLR) and platelet-to-lymphocyte ratio (PLR), evaluate the impact of the systemic inflammatory response observed in many malignancies on survival. There are a lot of studies showing, that platelets may protect CTC from damage in the circulation, they also stimulate EMT $(28,29)$, neutrophiles facilitate adhesion and colonisation to distant areas $(30,31)$ and lymphocytes play important role in protection against tumors by inducing cellular death (32). Nevertheless, SIRI was developed to combine in one index different parameters such as platelets, neutrophiles and lymphocytes, e.g. proinflammatory and immune status of patient, which could better predict prognosis of patients than different prognostic indexes separately.

Zhang et al. evaluated the association of SIRI with prognosis in 419 patients with advanced pancreatic carcinoma (locally advanced $27.5 \%$ and metastatic $72.5 \%$ ). By univariate and multivariate analysis, SIRI was found to be an independent predictor of OS. The group of patients with SIRI-low had better OS than the group of patients with SIRI-high $(p<0.0001)$. Prognostic significance of SIRI was confirmed regardless of Ca19-9 levels (33).

Similarly, Jomrich et al. evaluated the significance of SIRI, but in a group of patients who underwent radical resection for pancreatic carcinoma. The study comprised 321 patients. Blood samples were drawn during a period 7 days before surgery for the primary tumor. In univariate analysis, SIRIhigh was significantly associated with shorter OS $(p=0.007)$. 
in vivo $35: 31-39(2021)$

Table II. Studies evaluating impact of ctDNA on outcome of pancreatic carcinoma patients.

\begin{tabular}{|c|c|c|c|}
\hline Author & $\begin{array}{l}\text { Number of } \\
\text { patients }\end{array}$ & $\begin{array}{l}\text { ctDNA } \\
\text { positivity }\end{array}$ & Main findings \\
\hline Kruger $(20)$ & 54 & $36 / 54(67 \%)$ & $\begin{array}{l}\text { Presence of ctDNA significantly associated with shorter PFS and OS } \\
\text { Change in ctDNA concentration } \rightarrow \text { earlier predictor of response than CEA, Ca19-9 }\end{array}$ \\
\hline Lee $(21)$ & 37 & $23 / 37(62 \%)$ & $\begin{array}{l}\text { Median OS } 13.6 \text { months } v s . \text { not reached, HR } 4,1 ; p=0.015 \rightarrow \text { preoperativelly ctDNA+ } \\
\text { Median PFS } 10.3 \text { months } v s . \text { not reached, HR } 4,1 ; p=0.003 \rightarrow \text { preoperativelly ctDNA+ } \\
\text { Median OS } 10.6 \text { months } v s . \text { not reached, HR } 4,0 ; p=0.003 \rightarrow \text { postoperativelly ctDNA+ } \\
\text { Median PFS } 5.4 \text { months } v s .17,1 \text { months, HR } 5,4 ; p<0.001 \rightarrow \text { postoperativelly ctDNA+ }\end{array}$ \\
\hline Bernard (22) & 104 & NR & $\begin{array}{l}\text { ctDNA+ associated with shorter OS, HR } 2.36 ; p=0.018 \\
\text { ctDNA+ associated with shorter PFS, HR } 1.93 ; p=0.012\end{array}$ \\
\hline Watanabe (23) & 78 & NR & $\begin{array}{l}\text { ctDNA+ associated with prognosis during longitudinal follow-up; } p<0.001 \\
\text { (patients after surgery) } \\
\text { ctDNA+ associated with prognosis during longitudinal follow-up; } p=0.005 \\
\text { (patients wih no surgery) }\end{array}$ \\
\hline Perets (24) & 17 & $5 / 17(29.4 \%)$ & ctDNA+ associated with shorter OS $\rightarrow 8$ months $v s .37 .5$ months; $p<0.004$ \\
\hline \multirow[t]{2}{*}{ Pietrasz (25) } & 31 resectable & $6 / 31(19.3 \%)$ & $\begin{array}{l}\text { ctDNA+ associated with shorter OS } \rightarrow 19.3 \text { months } v s .32 .2 \text { months; } p=0.027 \\
\text { ctDNA+ associated with shorter PFS } \rightarrow 4.6 \text { months } v s .17 .6 \text { months; } p=0.03\end{array}$ \\
\hline & 104 advanced & $50 / 104(48 \%)$ & $\begin{array}{l}\text { ctDNA+ associated with shorter OS } \rightarrow 6.5 \text { months } v s .19 .0 \text { months; } \\
p<0.001 \text { in univariate analysis } \\
\text { HR } 1.96 ; p=0.007 \text { for OS in multivariate analysis }\end{array}$ \\
\hline Patel (26) & 94 & 70/94 (75\%) & $\begin{array}{l}\text { ctDNA+ associated with shorter OS } \rightarrow 6.3 \text { months } v s .11 .7 \text { months; } \\
p=0.001 \text { in univariate analysis } \\
\text { HR } 4.35 \text { for OS; } p=0.001 \text { in multivariate analysis }\end{array}$ \\
\hline
\end{tabular}

ctDNA: Circulating tumor DNA; OS: overall survival; PFS: progression-free survival; HR: hazard ratio; NR: not reported.

Table III. Studies evaluating systemic inflammatory response index (SIRI) and outcome of pancreatic carcinoma patients.

\begin{tabular}{lcl}
\hline Author & $\begin{array}{c}\text { Number of } \\
\text { patients }\end{array}$ & Main findings \\
\hline Zhang (33) & 419 & $\begin{array}{l}\text { SIRI-low patients have better OS than SIRI-high patients; } p<0.0001 \\
\text { Jomrich (34) }\end{array}$ \\
& 321 & SIRI-high patients associated with shorter OS, $p=0.007$ in univariate analysis \\
& & SIRI-high patients associated with shorter OS, $p=0.004$ in multivariate analysis \\
\hline
\end{tabular}

OS: Overall survival.

In multivariate analysis, SIRI remained an independent prognostic factor for OS $(p=0.004)$. Moreover, in multivariate analysis, there was no correlation between NLR, PLR and survival of patiets when evaluated as separate markers (34). The main results of studies on SIRI in pancreatic ductal adenocarcinoma are summarized in Table III.

Other Inflammation-based Prognostic Scores and Indexes

Besides SIRI, there are also different separate indexes for patients with malignancy, including pancreatic carcinoma. These include NLR (35-38), PLR (39), prognostic index (PI) (40), and the combination of albumin level and lymphocyte count in prognostic nutrition index (PNI) (41-43).

Another one is Glasgow score (GPS) and modified Glasgow score (mGPS) $(44,45)$. GPS was initially evaluated in patients with non-small cell lung cancer to assess relation of elevated CRP and low albumin levels with prognosis (46). Later, because some of studies were not able to show hypoalbuminemia as an independent predictor for OS, GPS was modified to emphasize the elevated CRP levels, known as mGPS (47). mGPS is able to better predict survival of patients regardless of primary tumor site (48).

A large study by Proctor et al. compared the relation of theses indexes and prognostic scores with the prediction of prognosis in patients with tumors. They evaluated 8,759 patients who had assessed blood samples during a 2-year period after diagnosis of their malignancy. Elevation of mGPS, NLR, PLR, PI and PNI were predictive of shorter cancer specific survival regardless to age, sex and location of tumor (all $p<0.001)$. Further, subanalysis showed that all immune-based indexes and scoring systems have prognostic 
significance, but especially mGPS and PI can be used for the assessment of prognosis of patients with cancer (49).

\section{Conclusion}

This short overview of studies evaluating the significance of CTCs and ctDNA, shows that they are very promising biomarkers, which could potentially lead to individualization of treatment for patients with pancreatic carcinoma. Analysis of these biomarkers provides a better assessment of the aggressiveness of disease and the prognosis of patients than the classic TNM classification and/or standard histopathologic evaluation of tumor specimens. Furthermore, CTCs and ctDNA are more sensitive in predicting metastatic spread than imaging methods (e.g. computed tomography). Similarly, prognostic scores and indexes may lead to individualization of treatment and a better assessment of prognosis. Their advantage is mainly the fact that they are easy to obtain by analysing selected values of blood counts and biochemistry, and that they are relatively cheap. Nevertheless, despite advances in the systemic treatment of patients with pancreatic carcinoma, there is room for improvement, which should lead to improvement in the prognosis of patients with this dismal disease.

\section{Conflicts of Interest}

The Authors state that there are no conflicts of interest regarding the publication of this article.

\section{Authors' Contributions}

Marian Liberko - Conceptualization, Writing - Original draft, Writing - Review and Editing; Katarina Kolostova - Writing Review and Editing; Arpad Szabo - Writing - Review and Editing; Robert Gurlich - Writing - Review and Editing; Martin Oliverius Writing - Review and Editing; Renata Soumarova - Supervision, Writing - Review and Editing.

\section{References}

1 Ferlay J, Colombet M, Soerjomataram I, Mathers C, Parkin DM, Piñeros M, Znaor A and Bray F: Estimating the global cancer incidence and mortality in 2018: GLOBOCAN sources and methods. Int J Cancer 144(8): 1941-1953, 2019. PMID: 30350310. DOI: 10.1002/ijc.31937

2 Siegel RL, Miller KD and Jemal A: Cancer statistics, 2019. CA Cancer J Clin 69(1): 7-34, 2019. PMID: 30620402. DOI: $10.3322 /$ caac. 21551

3 Ducreux M, Cuhna AS, Caramella C, Hollebecque A, Burtin P, Goéré D, Seufferlein T, Haustermans K, Van Laethem JL, Conroy T, Arnold D and ESMO Guidelines Committee: Cancer of the pancreas: ESMO Clinical Practice Guidelines for diagnosis, treatment and follow-up. Ann Oncol 26: v56-68, 2015. PMID: 26314780. DOI: 10.1093/annonc/mdv295
4 Neoptolemos JP, Palmer DH, Ghaneh P, Psarelli EE, Valle JW, Halloran CM, Faluyi O, O'Reilly DA, Cunningham D, Wadsley J, Darby S, Meyer T, Gillmore R, Anthoney A, Lind P, Glimelius B, Falk S, Izbicki JR, Middleton GW, Cummins S, Ross PJ, Wasan H, McDonald A, Crosby T, Ma YT, Patel K, Sherriff D, Soomal R, Borg D, Sothi S, Hammel P, Hackert T, Jackson R, Büchler MW and European Study Group for Pancreatic Cancer: Comparison of adjuvant gemcitabine and capecitabine with gemcitabine monotherapy in patients with resected pancreatic cancer (ESPAC-4): a multicentre, open-label, randomised, phase 3 trial. Lancet 389(10073): 1011-1024, 2017. PMID: 28129987. DOI: 10.1016/S0140-6736(16)32409-6

5 Conroy T, Hammel P, Hebbar M, Ben Abdelghani M, Wei AC, Raoul JL, Choné L, Francois E, Artru P, Biagi JJ, Lecomte T, Assenat E, Faroux R, Ychou M, Volet J, Sauvanet A, Breysacher G, Di Fiore F, Cripps C, Kavan P, Texereau P, Bouhier-Leporrier K, Khemissa-Akouz F, Legoux JL, Juzyna B, Gourgou S, O'Callaghan CJ, Jouffroy-Zeller C, Rat P, Malka D, Castan F, Bachet JB; Canadian Cancer Trials Group and the Unicancer-GIPRODIGE Group: FOLFIRINOX or Gemcitabine as Adjuvant Therapy for Pancreatic Cancer. N Engl J Med 379(25): 2395-2406, 2018. PMID: 30575490. DOI: 10.1056/NEJMoa1809775

6 Von Hoff DD, Ervin T, Arena FP, Chiorean EG, Infante J, Moore M, Seay T, Tjulandin SA, Ma WW, Saleh MN, Harris M, Reni M, Dowden S, Laheru D, Bahary N, Ramanathan RK, Tabernero J, Hidalgo M, Goldstein D, Van Cutsem E, Wei X, Iglesias J and Renschler MF: Increased survival in pancreatic cancer with nabpaclitaxel plus gemcitabine. N Engl J Med 369(18): 1691-703, 2013. PMID: 24131140. DOI: 10.1056/NEJMoa1304369

7 Conroy T, Desseigne F, Ychou M, Bouché O, Guimbaud R, Bécouarn Y, Adenis A, Raoul JL, Gourgou-Bourgade S, de la Fouchardière C, Bennouna J, Bachet JB, Khemissa-Akouz F, PéréVergé D, Delbaldo C, Assenat E, Chauffert B, Michel P, MontotoGrillot C, Ducreux M; Groupe Tumeurs Digestives of Unicancer and PRODIGE Intergroup: FOLFIRINOX versus gemcitabine for metastatic pancreatic cancer. N Engl J Med 364(19): 1817-1825, 2011. PMID: 21561347. DOI: 10.1056/NEJMoa1011923

8 Wang-Gillam A, Li CP, Bodoky G, Dean A, Shan YS, Jameson G, Macarulla T, Lee KH, Cunningham D, Blanc JF, Hubner RA, Chiu CF, Schwartsmann G, Siveke JT, Braiteh F, Moyo V, Belanger B, Dhindsa N, Bayever E, Von Hoff DD, Chen LT and NAPOLI-1 Study Group: Nanoliposomal irinotecan with fluorouracil and folinic acid in metastatic pancreatic cancer after previous gemcitabine-based therapy (NAPOLI-1): a global, randomised, open-label, phase 3 trial. Lancet 387(10018): 545-557, 2016. PMID: 26615328. DOI: 10.1016/S0140-6736(15)00986-1

9 Golan T, Hammel P, Reni M, Van Cutsem E, Macarulla T, Hall MJ, Park JO, Hochhauser D, Arnold D, Oh DY, ReinacherSchick A, Tortora G, Algül H, O’Reilly EM, McGuinness D, Cui KY, Schlienger K, Locker GY and Kindler HL: Maintenance olaparib for germline BRCA-mutated metastatic pancreatic cancer. N Engl J Med 381(4): 317-327, 2019. PMID: 31157963. DOI: $10.1056 /$ NEJMoa1903387

10 Liberko M, Kolostova K and Bobek V: Essentials of circulating tumor cells for clinical research and practice. Crit Rev Oncol Hematol 88(2): 338-356, 2013. PMID: 23830807. DOI: $10.1016 /$ j.critrevonc.2013.05.002

11 Effenberger KE, Schroeder C, Hanssen A, Wolter S, Eulenburg C, Tachezy M, Gebauer F, Izbicki JR, Pantel K and Bockhorn M: Improved risk stratification by circulating tumor cell counts 
in pancreatic cancer. Clin Cancer Resc 24(12): c2844-2850, 2018. PMID: 29559560. DOI: 10.1158/1078-0432.CCR-18-0120

12 Court CM, Ankeny JS, Sho S, Winograd P, Hou S, Song M, Wainberg ZA, Girgis MD, Graeber TG, Agopian VG, Tseng HR and Tomlinson JS: Circulating tumor cells predict occult metastatic disease and prognosis in pancreatic cancer. Ann Surg Oncol (4): 1000-1008, 2018. PMID: 29442211. DOI: 10.1245/s10434-0176290-8

13 Ma XL, Li YY, Zhang J, Huang JW, Jia HY, Liu L and Li P: Prognostic role of circulating tumor cells in patients with pancreatic cancer: a meta-analysis. Asian Pac J Cancer Prev 15(15): 60156020, 2014. PMID: 25124566. DOI: 10.7314/apjcp.2014. 15.15 .6015

14 Han L, Chen W and Zhao Q: Prognostic value of circulating tumor cells in patients with pancreatic cancer: a meta-analysis. Tumour Biol 35(3): 2473-2480, 2014. PMID: 24218336. DOI: 10.1007/s 13277-013-1327-5

15 Amantini C, Morelli MB, Nabissi M, Piva F, Marinelli O, Maggi F, Bianchi F, Bittoni A, Berardi R, Giampieri R and Santoni G: Expression profiling of circulating tumor cells in pancreatic ductal adenocarcinoma patients: biomarkers predicting overall survival. Front Oncol 9: 874, 2019. PMID: 31552188. DOI: 10.3389/fonc.2019.00874

16 Zhao XH, Wang ZR, Chen CL, Di L, Bi ZF, Li ZH and Liu YM: Molecular detection of epithelial-mesenchymal transition markers in circulating tumor cells from pancreatic cancer patients: Potential role in clinical practice. World J Gastroenterol 25(1): 138-150, 2019. PMID: 30643364. DOI: 10.3748/wjg.v25.i1.138

17 Poruk KE, Blackford AL, Weiss MJ, Cameron JL, He J, Goggins M, Rasheed ZA, Wolfgang CL and Wood LD: Circulating tumor cells expressing markers of tumor-initiating cells predict poor survival and cancer recurrence in patients with pancreatic ductal adenocarcinoma. Clin Cancer Res 23(11): 2681-2690, 2017. PMID: 27789528. DOI: 10.1158/1078-0432.CCR-16-1467

18 Bobek V, Gurlich R, Eliasova P, Kolostova K: Circulating tumor cells in pancreatic cancer patients: enrichment and cultivation. World J Gastroenterol 20(45): 17163-17170, 2014. PMID: 25493031. DOI: $10.3748 /$ wjg.v20.i45.17163

19 Jahr S, Hentze H, Englisch S, Hardt D, Fackelmayer FO, Hesch RD and Knippers R: DNA fragments in the blood plasma of cancer patients: quantitations and evidence for their origin from apoptotic and necrotic cells. Cancer Res 61(4): 1659-1665, 2001. PMID: 11245480.

20 Kruger S, Heinemann V, Ross C, Diehl F, Nagel D, Ormanns S, Liebmann S, Prinz-Bravin I, Westphalen CB, Haas M, Jung A, Kirchner T, von Bergwelt-Baildon M, Boeck S and Holdenrieder S: Repeated mutKRAS ctDNA measurements represent a novel and promising tool for early response prediction and therapy monitoring in advanced pancreatic cancer. Ann Oncol 29(12): 2348-2355, 2018. PMID: 30346475. DOI: 10.1093/annonc/mdy417

21 Lee B, Lipton L, Cohen J, Tie J, Javed AA, Li L, Goldstein D, Burge M, Cooray P, Nagrial A, Tebbutt NC, Thomson B, Nikfarjam M, Harris M, Haydon A, Lawrence B, Tai DWM, Simons K, Lennon AM, Wolfgang CL, Tomasetti C, Papadopoulos N, Kinzler KW, Vogelstein B and Gibbs P: Circulating tumor DNA as a potential marker of adjuvant chemotherapy benefit following surgery for localized pancreatic cancer. Ann Oncol 30(9): 14721478, 2019. PMID: 31250894. DOI: 10.1093/annonc/mdz200

22 Bernard V, Kim DU, San Lucas FA, Castillo J, Allenson K, Mulu FC, Stephens BM, Huang J, Semaan A, Guerrero PA,
Kamyabi N, Zhao J, Hurd MW, Koay EJ, Taniguchi CM, Herman JM, Javle M, Wolff R, Katz M, Varadhachary G, Maitra A and Alvarez HA: Circulating nucleic acids are associated with outcomes of patients with pancreatic cancer. Gastroenterology 156(1): 108-118.e4, 2019. PMID: 30240661. DOI: 10.1053/ j.gastro.2018.09.022

23 Watanabe F, Suzuki K, Tamaki S, Abe I, Endo Y, Takayama Y, Ishikawa H, Kakizawa N, Saito M, Futsuhara K, Noda H, Konishi F and Rikiyama T: Longitudinal monitoring of KRASmutated circulating tumor DNA enables the prediction of prognosis and therapeutic responses in patients with pancreatic cancer. PLoS One 14(12): e0227366, 2019. PMID: 31891652. DOI: 10.1371/journal.pone.0227366

24 Perets R, Greenberg O, Shentzer T, Semenisty V, Epelbaum R, Bick T, Sarji S, Ben-Izhak O, Sabo E and Hershkovitz D: Mutant KRAS circulating tumor DNA is an accurate tool for pancreatic cancer monitoring. Oncologist 23(5): 566-572, 2018. PMID: 29371474. DOI: 10.1634/theoncologist.2017-0467

25 Pietrasz D, Pécuchet N, Garlan F, Didelot A, Dubreuil O, Doat S, Imbert-Bismut F, Karoui M, Vaillant JC, Taly V, Laurent-Puig P and Bachet JB: Plasma circulating tumor DNA in pancreatic cancer patients is a prognostic marker. Clin Cancer Res 23(1): 116-123, 2017. PMID: 27993964. DOI: 10.1158/1078-0432.CCR-16-0806

26 Patel H, Okamura R, Fanta P, Patel C, Lanman RB, Raymond VM, Kato $\mathrm{S}$ and Kurzrock R: Clinical correlates of blood-derived circulating tumor DNA in pancreatic cancer. J Hematol Oncol 12(1): 130, 2019. PMID: 31801585. DOI: 10.1186/s13045-019-0824-4

27 Hu B, Yang XR, Xu Y, Sun YF, Sun C, Guo W, Zhang X, Wang WM, Qiu SJ, Zhou J and Fan J: Systemic immune-inflammation index predicts prognosis of patients after curative resection for hepatocellular carcinoma. Clin Cancer Res 20(23): 6212-6222, 2014. PMID: 25271081. DOI: 10.1158/1078-0432.CCR-14-0442

28 Labelle M, Begum S and Hynes RO: Direct signaling between platelets and cancer cells induces an epithelial-mesenchymal-like transition and promotes metastasis. Cancer Cell 20(5): 576-590, 2011. PMID: 22094253. DOI: 10.1016/j.ccr.2011.09.009

29 Schumacher D, Strilic B, Sivaraj KK, Wettschureck N and Offermanns S: Platelet-derived nucleotides promote tumor-cell transendothelial migration and metastasis via $\mathrm{P} 2 \mathrm{Y} 2$ receptor. Cancer Cell 24(1): 130-137, 2013. PMID: 23810565. DOI: 10.1016/j.ccr.2013.05.008

30 Stotz M, Gerger A, Eisner F, Szkandera J, Loibner H, Ress AL, Kornprat P, AlZoughbi W, Seggewies FS, Lackner C, Stojakovic T, Samonigg H, Hoefler G and Pichler M: Increased neutrophillymphocyte ratio is a poor prognostic factor in patients with primary operable and inoperable pancreatic cancer. Br J Cancer 109(2): 416421, 2013. PMID: 23799847. DOI: 10.1038/bjc.2013.332

31 Cools-Lartigue J, Spicer J, McDonald B, Gowing S, Chow S, Giannias B, Bourdeau F, Kubes P and Ferri L: Neutrophil extracellular traps sequester circulating tumor cells and promote metastasis. J Clin Invest 123(8): 3446-3458, 2013. PMID: 23863628. DOI: $10.1172 / \mathrm{JCI} 67484$

32 Mantovani A, Allavena P, Sica A and Balkwill F: Cancer-related inflammation. Nature 454(7203): 436-444, 2008. PMID: 18650914. DOI: 10.1038 /nature07205

33 Zhang K, Hua YQ, Wang D, Chen LY, Wu CJ, Chen Z, Liu LM and Chen $\mathrm{H}$ : Systemic immune-inflammation index predicts prognosis of patients with advanced pancreatic cancer. J Transl Med 17(1): 30, 2019. PMID: 30658662. DOI: 10.1186/s12967019-1782-x 
34 Jomrich G, Gruber ES, Winkler D, Hollenstein M, Gnant M, Sahora K and Schindl M: Systemic immune-inflammation index (SII) predicts poor survival in pancreatic cancer patients undergoing resection. J Gastrointest Surg 24(3): 610-618, 2020. PMID: 30923999. DOI: 10.1007/s11605-019-04187-z

35 Walsh SR, Cook EJ, Goulder F, Justin TA and Keeling NJ: Neutrophil-lymphocyte ratio as a prognostic factor in colorectal cancer. J Surg Oncol 91(3): 181-184, 2005. PMID: 16118772. DOI: $10.1002 /$ jso.20329

36 Sarraf KM, Belcher E, Raevsky E, Nicholson AG, Goldstraw P and Lim E: Neutrophil/lymphocyte ratio and its association with survival after complete resection in non-small cell lung cancer. J Thorac Cardiovasc Surg 137(2): 425-428, 2009. PMID: 19185164. DOI: $10.1016 /$ j.jtcvs.2008.05.046

37 Kao SC, Pavlakis N, Harvie R, Vardy JL, Boyer MJ, van Zandwijk $\mathrm{N}$ and Clarke SJ: High blood neutrophil-tolymphocyte ratio is an indicator of poor prognosis in malignant mesothelioma patients undergoing systemic therapy. Clin Cancer Res 16(23): 5805-5813, 2010. PMID: 20956618. DOI: 10.1158/1078-0432.CCR-10-2245

38 Cho H, Hur HW, Kim SW, Kim SH, Kim JH, Kim YT, and Lee $\mathrm{K}$ : Pre-treatment neutrophil to lymphocyte ratio is elevated in epithelial ovarian cancer and predicts survival after treatment. Cancer Immunol Immunother 58(1): 15-23, 2009. PMID: 18414853. DOI: 10.1007/s00262-008-0516-3.

39 Smith RA, Bosonnet L, Raraty M, Sutton R, Neoptolemos JP, Campbell F and Ghaneh P: Preoperative platelet-lymphocyte ratio is an independent significant prognostic marker in resected pancreatic ductal adenocarcinoma. Am J Surg 197(4): 466-472, 2009. PMID: 18639229. DOI: 10.1016/j.amjsurg.2007.12.057

40 Kasymjanova G, MacDonald N, Agulnik JS, Cohen V, Pepe C, Kreisman H, Sharma R and Small D: The predictive value of pre-treatment inflammatory markers in advanced non-small-cell lung cancer. Curr Oncol 17(4): 52-58, 2010. PMID: 20697515. DOI: $10.3747 /$ co.v17i4.567

41 Kanda M, Fujii T, Kodera Y, Nagai S, Takeda S and Nakao A: Nutritional predictors of postoperative outcome in pancreatic cancer. Br J Surg 98(2): 268-274, 2011. PMID: 20960457. DOI: 10.1002/bjs.7305

42 Nozoe T, Ninomiya M, Maeda T, Matsukuma A, Nakashima $H$ and Ezaki T: Prognostic nutritional index: a tool to predict the biological aggressiveness of gastric carcinoma. Surg Today 40(5): 440-443, 2010. PMID: 20425547. DOI: 10.1007/s00595009-4065-y
43 Nozoe T, Kimura Y, Ishida M, Saeki H, Korenaga D and Sugimachi K: Correlation of pre-operative nutritional condition with post-operative complications in surgical treatment for oesophageal carcinoma. Eur J Surg Oncol 28(4): 396-400, 2002. PMID: 12099649. DOI: 10.1053/ejso.2002.1257

44 Proctor MJ, Talwar D, Balmar SM, O'Reilly DS, Foulis AK, Horgan PG, Morrison DS and McMillan DC: The relationship between the presence and site of cancer, an inflammation-based prognostic score and biochemical parameters. Initial results of the Glasgow Inflammation Outcome Study. Br J Cancer 103(6): 870-876, 2010. PMID: 20717110. DOI: 10.1038/sj.bjc.6605855

45 Proctor MJ, Morrison DS, Talwar D, Balmer SM, O'Reilly DS, Foulis AK, Horgan PG and McMillan DC: An inflammationbased prognostic score (mGPS) predicts cancer survival independent of tumour site: a Glasgow Inflammation Outcome Study. Br J Cancer 104(4): 726-734, 2011. PMID: 21266974. DOI: $10.1038 /$ sj.bjc.6606087

46 Forrest LM, McMillan DC, McArdle CS, Angerson WJ and Dunlop DJ: Evaluation of cumulative prognostic scores based on the systemic inflammatory response in patients with inoperable non-small-cell lung cancer. Br J Cancer 89(6): 10281030, 2003. PMID: 12966420. DOI: 10.1038/sj.bjc.6601242

47 McMillan DC, Crozier JE, Canna K, Angerson WJ and McArdle CS: Evaluation of an inflammation-based prognostic score (GPS) in patients undergoing resection for colon and rectal cancer. Int J Colorectal Dis 22(8): 881-886, 2007. PMID: 17245566. DOI: $10.1007 / \mathrm{s} 00384-006-0259-6$

48 Proctor MJ, Morrison DS, Talwar D, Balmer SM, O’Reilly DS, Foulis AK, Horgan PG and McMillan DC: An inflammationbased prognostic score (mGPS) predicts cancer survival independent of tumour site: a Glasgow Inflammation Outcome Study. Br J Cancer 104(4): 726-734, 2011. PMID: 21266974. DOI: $10.1038 /$ sj.bjc.6606087

49 Proctor MJ, Morrison DS, Talwar D, Balmer SM, Fletcher CD, O'Reilly DS, Foulis AK, Horgan PG and McMillan DC: A comparison of inflammation-based prognostic scores in patients with cancer. A Glasgow Inflammation Outcome Study. Eur J Cancer 47(17): 2633-2641, 2011. PMID: 21724383. DOI: 10.1016/j.ejca.2011.03.028

Received October 29, 2020

Revised November 19, 2020

Accepted November 21, 2020 